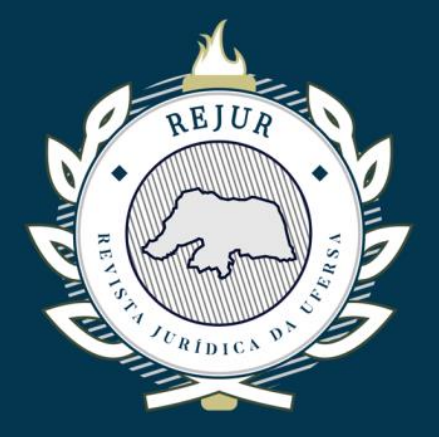

\title{
REFORMAS INSTITUCIONAIS NA SEGURANÇA PÚBLICA: CONTRIBUIÇÕES DA JUSTIÇA DE TRANSIÇÃO E DO DIREITO E DESENVOLVIMENTO
}

POLICE INSTITUTIONAL REFORMS: CONTRIBUTIONS FROM TRANSITIONAL JUSTICE AND LAW AND DEVELOPMENT

\author{
MARIA PIA GUERRA*
}

\section{RESUMO}

O estudo de reformas institucionais pode partir, dentre outros campos, da justiça de transição (JT), dos direitos humanos e do direito e desenvolvimento (D\&D). A opção por um ou outro eixo leva a distintos impasses. $\mathrm{O}$ artigo analisa as contribuições dos três campos teóricos ao estudo das reformas institucionais, buscando comparar e contrastar os seus limites e potencialidades. Toma como estudo de caso as reformas da segurança pública no Brasil, para identificar desafios práticos que podem ser esclarecidos por estas abordagens teóricas, tanto nas etapas de formulação como de implementação. Conclui com as recomendações de atenção à segmentação social e aos obstáculos de natureza material, cultural e política.

Palavras-chave: Reformas institucionais. Justiça de transição. Direito e desenvolvimento. Segurança pública.

\section{ABSTRACT}

Both transitional justice (JT) and law and development (D \& D) study institutional reforms of police forces, leading to different impasses. The article analyzes the contributions of these two theoretical fields to the study of institutional reforms. It takes as a case study the police organization in Brazil, in order to identify practical challenges in development and enforcement that can be clarified by these theoretical approaches. In conclusion, it describes the recommendations for attention to social segmentation and obstacles of a material, cultural and political nature.

Keywords: Institutional reforms. Transitional justice. Law and development. Police forces.

* Doutora e Mestre em Direito pela Universidade de Brasília (UnB).

Professora da Faculdade de Direito da UnB.

mapiaguerra@gmail.com 


\section{SUMÁRIO}

\section{INTRODUÇÃO; 1 REFORMAS INSTITUCIONAIS NA JUSTIÇA DE TRANSIÇÃO: OS LIMITES DO DEBATE; 2 REFORMAS INSTITUCIONAIS NO SISTEMA INTERAMERICANO DE DIREITOS HUMANOS; 3 REFORMAS INSTITUCIONAIS NO DIREITO E DESENVOLVIMENTO; 4 DESAFIOS PARA AS REFORMAS INSTITUCIONAIS NA SEGURANÇA PÚBLICA NO BRASIL; 4.1. É preciso reformar o sistema de segurança?; 4.2. A reforma e a estratégia de implementação: entre o estado de direito e a sociedade; 4.3. A reforma e a estratégia de implementação: entre o governo federal e os entes locais; CONSIDERAÇÕES FINAIS; REFERÊNCIAS.}

\section{INTRODUÇÃO}

Embora exista algum consenso teórico nas ciências sociais sobre a importância das instituições para a transformação social, existe também, paradoxalmente, uma relativa incompreensão sobre a medida e a operacionalidade desta relação. Instituições importam, mas quais e como? A resposta para esta pergunta, diriam os mais otimistas, seria a chave para a produção da transformação social desejada.

Esta relação entre teoria e prática que aqui apontamos anuncia o interesse e as dificuldades no campo de estudo das reformas institucionais. Se por um lado reconhecemos que as reformas, assim como políticas públicas, são fundamentais, por outro temos poucos instrumentos analíticos para identificar os padrões e os processos de alteração. A reflexão acadêmica sobre o tema e a prática de reforma ainda são bastante desconectadas, ao menos no Brasil. E os estudos existentes parecem concentrar-se sobre casos específicos, em campos teóricos distintos. Ficamos com poucos recursos para identificar os possíveis erros e acertos das futuras iniciativas de um modo mais geral.

Neste artigo buscaremos comparar campos teóricos distintos que tratam do tema reformas institucionais, no intuito de identificar os pontos de convergência e divergência, as possibilidades e os limites de suas reflexões para o aprofundamento do debate. Para tanto, utilizaremos um eixo comum, que é o de reforma das instituições de segurança pública. Este eixo interessa não apenas pela sua importância em si e por ser objeto de estudo dos campos selecionados, mas porque é um dos casos-modelo das dificuldades resultantes do distanciamento entre teoria e prática que anunciamos acima.

$\mathrm{O}$ artigo tem a seguinte estrutura. Primeiro, descreveremos o debate sobre as reformas institucionais no (2) campo da justiça de transição (JT) e dos (3) direitos humanos, e a seguir (4) no campo do direito e desenvolvimento (D\&D). Neste espaço anunciaremos as principais características já apontadas pela literatura. Terceiro, analisaremos (5) o caso da reforma das instituições de segurança pública. Neste espaço, iremos tensionar as contribuições dos três campos teóricos, no intuito de comparar e contrastar os seus limites e potencialidades. Ao final, indicaremos os elementos que podem ser aprofundados em estudos posteriores. 


\section{REFORMAS INSTITUCIONAIS NA JUSTIÇA DE TRANSIÇÃO: OS LIMITES DO DEBATE}

Para compreender os limites do debate sobre reformas institucionais dentro do campo da justiça de transição, partimos de duas constatações. Primeiro, existe um certo consenso teórico acerca do conceito de justiça transicional. Em documento das Nações Unidas, seria o "amplo conjunto de processos e mecanismos associados às tentativas de uma sociedade de dar conta dos legados de abusos cometidos em larga-escala no passado, no intuito de assegurar responsividade, garantir justiça e alcançar reconciliação". ${ }^{1}$ Estes processos poderiam ser classificados em quatro pilares, tal como consolidado por Ruti Teitel, que incluiriam o direito à memória e à verdade sobre os fatos ocorridos, o direito à responsabilização dos perpetradores de graves violações de direitos humanos, o direito à reparação para as vítimas e o direito às reformas institucionais necessárias à construção de uma sociedade democrática. ${ }^{2}$ Este último, de acordo com o International Center for Transitional Justice, abarcaria as seguintes medidas:

- Expurgo de oficiais: investigação de antecedentes pessoais para responsabilizar e afastar do serviço público aqueles oficiais envolvidos em práticas abusivas ou corruptas;

- Reformas estruturais: reestruturação das instituições para promover integridade e legitimidade, garantindo responsividade, independência funcional e representação democrática;

- Controle: criação de órgãos de controle internos públicos e transparentes, para garantir responsividade à governança civil;

- Transformação dos regimes jurídicos: reforma e criação de regimes jurídicos que garantam proteção e a promoção dos direitos humanos, seja por meio de emendas constitucionais ou da incorporação de tratados internacionais de direitos humanos;

- Desarmamento, desmobilização e reintegração: dissolução de grupos armados e paramilitares e promoção de medidas - sensíveis à justiça - por meio das quais ex-combatentes possam ser reintegrados à sociedade civil;

- $\quad$ Educação: criação de programas de treinamento para agentes públicos sobre os parâmetros de direitos humanos nacionais e internacionais. ${ }^{3}$

Segundo, existe ao menos uma suspeita generalizada de que dentre estes o compromisso com as reformas institucionais seria o menos desenvolvido tanto na teoria como

\footnotetext{
${ }^{1}$ No original: "For the United Nations, transitional justice is the full range of processes and mechanisms associated with a society's attempt to come to terms with a legacy of large-scale past abuses, in order to ensure accountability, serve justice and achieve reconciliation" (NAÇÕES UNIDAS. Guidance Note of the SecretaryGeneral: United Nations Approach to Transitional Justice. Nova lorque, março de 2010).

2 TEITEL, R. Transitional Justice. New York: Oxford University Press, 2000.

${ }^{3}$ MAYER-RIECKH, A; GREIFF, P. Justice as Prevention: Vetting Public Employees in Transitional Societies. Nova lorque: Social Science Research Council, 2007.
} 
na prática. ${ }^{4}$ Comissões da Verdade se alastraram pela América Latina e pelo mundo nos últimos vinte anos. ${ }^{5}$ Programas de reparação mais ou menos extensos tornaram-se política de diversos Estados. ${ }^{6} \mathrm{E}$ mesmo ações de responsabilização judicial avançaram nas esferas penais e civis. ${ }^{7}$ Iniciativas de reforma institucional, no entanto, tardaram a ser incorporadas às políticas internacionais e aos estudos teóricos e empíricos da área. Assim, por exemplo, no início dos anos 1990 a Autoridade Transicional das Nações Unidas para o Camboja (UN Transitional Authority for Cambodia - UNTAC) não obteve autorização para participar de reformas institucionais no sistema legal do país por ausência de mandato explícito nos Acordos de Paris. A limitação se tornou uma questão para o grupo na medida em que percebiam que embora estivesse dentro de sua competência supervisionar a efetividade das leis e processos judiciais, cumpriam o mandato em um sistema legal que não conhecia o princípio da independência judicial. ${ }^{8}$ Muitos dos objetivos dependiam de uma forma liberal de Estado, de natureza diversa da existente na estrutura administrativa anterior.

O exemplo revela os desafios de um projeto de reforma institucional e, em última instância, os limites da justiça de transição. Qual o ponto de partida e de chegada da transição na qual se deve realizar a justiça? Ou, como descreveriam os primeiros autores da transitologia, mediante quais requisitos se completa a almejada consolidação democrática? No exemplo citado, a diferença de natureza entre os sistemas legais nos leva a indagar se existe afinal apenas um modelo de rule of law e uma receita de implantação.

Por certo, uma visão abrangente de justiça de transição exige a inclusão de políticas de reforma institucional, sem as quais a reparação e a responsabilização tornar-se-iam inócuas. O próprio Conselho de Direitos Humanos das Nações Unidas reconheceu, na 25a sessão em março de 2014, referindo-se ao Sri Lanka, a necessidade de uma abordagem compreensiva de justiça transicional, que abarcasse as medidas capazes de fortalecer o ambiente institucional legal daquele país. A questão porém é: qual política de qual reforma institucional?

O objetivo aqui, vale notar, não é avançar a crítica a um projeto global de justiça transicional, como desenvolvido por Rosemary Nagy, mas indagar se a falta de reflexão sobre o modelo de democracia em horizonte - "o ponto final da transição" - não é justamente uma das razões para o esvaziamento dos programas de reformas institucionais no âmbito da justiça de transição. ${ }^{9}$

O fato é que a pouca operatividade das categorias não significou, a contrário senso, a ausência de reformas. Como descrito por Thomas Carothers em artigo amplamente citado,

\footnotetext{
${ }^{4}$ WEICHERT, M. The role of institutional reform in transitional justice and the obstacles for its development. Trabalho apresentado na Global Fellows Forum, Hauser Global Program, New York University. Nova lorque, 7 out. 2014.

${ }^{5}$ HAYNER, P. Unspeakable truths. Facing the challenge of Truth Commissions. 2 ed. New York, London: Routledge, 2010.

${ }^{6}$ ABRÃO, P; TORELLY, M. O programa de reparações como eixo estruturante da Justiça de Transição no Brasil. In: F Reátegui (org.). Justiça de Transição: Manual para a América Latina. Brasília/Nova lorque: Ministério da Justiça/ICTJ, 2011, p. 473-516.

${ }^{7}$ OSMO, C. Judicialização da justiça de transição na América Latina. Brasília: Ministério da Justiça, Comissão de Anistia, Rede Latino-Americana de Justiça de Transição, 2016.

${ }^{8}$ FERNANDO, B. Editorial: Institutional Reforms as an Integral Part of a Comprehensive Approach to Transitional Justice. International Journal of Transitional Justice, v. 8, 2014, 187-193.

${ }^{9}$ NAGY, R. Transitional Justice as Global Project: critical reflections. Third World Quarterly, v. 29, n. 2, pp. 275289, 2008.
} 
um "renascimento do Estado de direito" ("rule of law revival"10) se estendeu por toda a política internacional durante as décadas de 1990 e 2000. Apenas o Banco Mundial, de 1990 a 2010, apoiou 330 projetos de fortalecimento de instituições de Estado de direito, dispendendo cerca de US\$ 2.9 bilhões no setor. ${ }^{11}$ Foram investimentos do Banco no projeto governance matters, definidos a partir de análise periódica de mais de 200 países quanto à efetividade de indicadores de governança em seis áreas: voz e responsabilidade, estabilidade política e ausência de violência/terrorismo, eficiência governamental, qualidade regulatória e normativa, Estado de direito e controle da corrupção. ${ }^{12}$

Estes projetos inspiravam-se em duas perspectivas. De um lado, uma perspectiva instrumental, associada à Institutional Economics, que enfatizava as relações entre o crescimento econômico (níveis de investimento) e o comprometimento a padrões institucionais (estabilidade e proteção da propriedade). ${ }^{13}$ De outro, uma perspectiva deontológica, liderada por Amartya Sen, que ampliando o conceito de desenvolvimento incluía ainda outras dimensões da vida humana. O embate entre as duas posições refletia concepções distintas de Estado de direito. Se por um lado concepções formalistas teriam a vantagem de não sobrecarregar a análise com imperialismo cultural, de outro foram consideradas insuficientes por não levar em consideração o quadro moral local e as práticas de efetivação. ${ }^{14}$

No Brasil, neste mesmo período, diversos projetos pretenderam adequar as instituições brasileiras ao novo contexto democrático nacional e mundial. $\mathrm{Na}$ seara administrativa, por exemplo, o governo Fernando Henrique Cardoso, com a liderança direta de Bresser Pereira, divulgou e buscou implantar um amplo programa de reforma do Estado destinado a reduzir o patrimonialismo e a ineficiência, considerados, à semelhança do discurso de justiça transicional, heranças do passado brasileiro, o que se faria por meio de repasse de competências antes estatais ao terceiro setor e à iniciativa privada e da criação de agências reguladoras para as competências remanescentes.

\footnotetext{
10 "One cannot get through a foreign policy debate these days without someone proposing the rule of law as a solution to the world's troubles. How can U.S. policy on China cut through the conundrum of balancing human rights against economic interests? Promoting the rule of law, some observers argue, advances both principles and profits. What will it take for Russia to move beyond Wild West capitalism to more orderly market economics? Developing the rule of law, many insist, is the key. How can Mexico negotiate its treacherous economic, political, and social transitions? Inside and outside Mexico, many answer: establish once and for all the rule of law. Indeed, whether it's Bosnia, Rwanda, Haiti, or elsewhere, the cure is the rule of law, of course ... . The concept is suddenly everywhere-a venerable part of Western political philosophy enjoying a new run as a rising imperative of the era of globalization. Unquestionably, it is important to life in peaceful, free, and prosperous societies. Yet its sudden elevation as a panacea for the ills of countries in transition from dictatorships or statist economies should make both patients and prescribers wary. The rule of law promises to move countries past the first, relatively easy phase of political and economic liberalization to a deeper level of reform. But that promise is proving difficult to fulfill" (CAROTHERS, T. The Rule of Law Revival. Foreign Affairs, v. 77, n. 95, 1998).

${ }_{11}$ PRADO, M. The paradox of rule of law reforms: how early reforms can create obstacles to future ones. Rev. Sociol. Politica, Curitiba, v. 21, n. 45, mar. 2013.

12 KAUFMANN; KRAAY; MASTRUZZI. Governance Matters VI: Governance Indicators for 1996-2006. World Bank Policy Research Working Paper n. 4280, jul. 2007

13 NORTH, D.C. Institutional Change: a framework of analyses. 1999. Disponível em http://ecsocman.hse.ru/data/853/760/1216/9412001.pdf. Acesso 28 de junho de 2012.

${ }^{14}$ DANIELS, R; TREBILCOCK, M. The Political Economy of Rule of Law Reform in Developing Countries. Michigan Journal of International Law, v. 26, n. 1, 2004
} 
O mesmo pode ser dito para a reforma do sistema de justiça, uma das medidas previstas nos estudos de justiça transicional. Em 1996, o Banco Mundial publicou o Documento n. 319, intitulado "O setor judiciário na América Latina e no Caribe: Elementos para reforma", contendo relatório dos gargalos institucionais de sistemas legais de toda a região. ${ }^{15}$ Conforme descrito no prefácio do Diretor SriRam Aiyer, o documento tinha por objetivo auxiliar os países da América Latina e do Caribe, que então passavam por grandes ajustes do papel do Estado e da iniciativa privada, a melhorar a eficiência do judiciário, garantindo transparência, previsibilidade de decisões e melhoria do ambiente de negócios. ${ }^{16}$ Sugere medidas que foram posteriormente adotadas pelo Brasil, em especial pela Emenda Constitucional n. 45 de 2004, como a criação de órgão de controle externo - o Conselho Nacional de Justiça -, a verticalização das decisões na cúpula do judiciário e a criação de mecanismos alternativos de resolução de conflitos.

Neste debate, ao menos no que se refere ao público brasileiro, as categorias tradicionais de justiça de transição acrescentaram pouco, não tanto por falta de oportunidade política, mas ora por falta de clareza sobre seus objetivos, ora por uma decisão, possivelmente acertada, de autocontenção conceitual. Em que sentidos e referente a quais medidas a reforma do sistema de justiça no Brasil em 2004 foi ou não adequada a uma nova democracia, considerando, inclusive, que algumas medidas, como a criação de um órgão de controle externo para o judiciário, estão também previstas nas análises de justiça transicional? No que se refere às demais medidas, como o destaque concedido às medidas para melhorar a previsibilidade e a celeridade das decisões judiciais, promotoras, segundo o modelo, de maior eficiência negocial, seria esta também uma medida defendida pela justiça transicional? Ou ainda, que tipo de legados (fatores históricos políticos e sociais, produzidos com ou sem respaldo do regime autoritário) deveriam ter sido levados em consideração para esta reforma? Seriam os mesmos referidos por Bresser Pereira, como a gestão patrimonialista e a gestão burocrática, em muito anteriores à instalação de um governo militar? Afinal, com quais

\footnotetext{
15 DAKOLIAS, M. O setor judiciário na América Latina e no Caribe: Elementos para reforma. Documento técnico n. 319, Banco Mundial. Nova lorque: Banco Mundial, 1996

16 "Durante a década de 80, as abordagens desenvolvimentistas focalizavam uma agenda macro econômica que, sem necessidade, teve prioridade sobre as reformas institucionais. 'Por décadas, os governos na América Latina falharam em desenvolver instituições necessárias em resolver os problemas básicos da população tendo em vista que concentravam a maioria de seus recursos no gerenciamento de seus ativos e passivos e na regulação de quase todos os aspectos da vida econômica'. Todavia, como a estabilidade econômica tornou-se parte da realidade, muitos países passaram a trabalhar buscando a equidade social, bem como as reformas políticas e econômicas. Como resultado, o processo de desenvolvimento passa a envolver as reformas de segunda geração com um propósito mais amplo de focalizar as reformas institucionais, como a reforma do judiciário. Nas palavras de um Ministro de Justiça, não basta construir rodovias e fábricas para modernizar o estado ... um sistema de justiça confiável também é necessário'. (...). Objetivos da reforma do judiciário. A reforma econômica requer um bom funcionamento do judiciário o qual deve interpretar e aplicar as leis e normas de forma previsível e eficiente. Com a emergência da abertura dos mercados aumenta a necessidade de um sistema jurídico. Com a transição de uma economia familiar - que não se baseava em leis e mecanismos formais para resolução de conflitos - para um aumento nas transações entre atores desconhecidos cria-se a necessidade de maneiras de resolução de conflitos de modo formal. As novas relações comerciais demandam decisões imparciais com a maior participação de instituições formais. Todavia, o atual sistema jurídico é incapaz de satisfazer esta demanda, forçando, consequentemente, as partes a continuar dependendo de mecanismos informais, relações familiares ou laços pessoais para desenvolver os negócios. Algumas vezes isto desestimula as transações comerciais com atores desconhecidos possivelmente mais eficientes gerando uma distribuição ineficiente de recursos. Esta situação adiciona custos e riscos as transações comerciais e assim reduz o tamanho dos mercados, e consequentemente, a competitividade do mercado" (DAKOLIAS, M. O setor judiciário na América Latina e no Caribe: Elementos para reforma. Documento técnico n. 319, Banco Mundial. Nova lorque: Banco Mundial, 1996).
} 
critérios podemos avaliar o projeto de desenvolvimento (ou de consolidação democrática) que embasou estes planos de reforma do Estado de direito?

É de se notar que as dificuldades de análise e implementação das reformas não foram exclusivas do campo da justiça de transição. A euforia inicial quanto aos projetos do Governance Matters deu lugar nos últimos anos a algum ceticismo, uma vez que os resultados dos investimentos ficaram longe do esperado. $O$ destaque para as reformas de melhoria do ambiente contratual e imobiliário, por exemplo, foi contraposto à diversidade de arranjos de propriedade existentes no mundo. Como mostram Trebilcock e Daniels (2004), em estudo sobre reformas frustradas na África, Ásia, América Latina e Leste Europeu, pouco se sabe ainda sobre como conduzir reformas institucionais bem sucedidas para o desenvolvimento econômico e social. Ainda, pode-se avançar, considerando que reformas são processos negociados, pouco se sabe sobre quais reformas são fundamentais e em qual ordem de prioridades.

\section{REFORMAS INSTITUCIONAIS NO SISTEMA INTERAMERICANO DE DIREITOS HUMANOS}

As recomendações da Corte Interamericana de Direitos Humanos (CIDH) são um bom ponto de partida para tensionar as contribuições do campo dos direitos humanos - e justiça de transição - às reformas institucionais, tanto as relativas ao sistema de justiça como e especialmente, aqui, as relativas à segurança pública.

Tomando como eixo as decisões da CIDH no âmbito da justiça de transição, seguimos análise de Calabria para sumarizar as suas recomendações de modificação legislativa dos Estados nacionais. ${ }^{17}$ Quanto ao uso desproporcional de força por instituições e agentes responsáveis pelo cumprimento da lei, a corte recomendou em seus julgados, dentre outras medidas, a codificação de delitos como tortura, execução extrajudicial e desaparecimento forçado, a ratificação de convenções internacionais e a adaptação de procedimentos das organizações policiais às normas internacionais. ${ }^{18}$ Quanto às liberdades de pensamento e expressão e direitos político-eleitorais, exigiu a adaptação das legislações nacionais à proteção conferida no âmbito internacional. ${ }^{19}$

17 CALABRIA, C. Alterações normativas, transformações sociojurídicas: analisando a eficácia da Corte Interamericana de Direitos Humanos. Rev. Direito e Práx., Rio de Janeiro, v. 8, n. 2, pp. 1286-1355, 2017.

${ }^{18}$ Ver Caso Barrios Altos v. Peru, Caso Bámaca Velásquez v. Guatemala, Caso Goiburú et al v. Paraguai, Caso Heliodoro-Portugal v. Panamá (CALABRIA, C. Alterações normativas, transformações sociojurídicas: analisando a eficácia da Corte Interamericana de Direitos Humanos. Rev. Direito e Práx., Rio de Janeiro, v. 8, n. 2, pp. 12861355, 2017).

${ }^{19}$ Ainda, quanto à jurisdição militar, recomenda que esta se restrinja, caso exista, aos delitos relativos a funções militares e cometidos por militares em serviço ativo (Ver Caso Cabrera García e Montiel-Flores v. México, Caso Fernández Ortega et al v. México, Caso Radilla Pacheco v. México, Caso Rosendo-Cantú et al v. México). Quanto às leis de anistia e exceção, exige sejam destituídas de eficácia ou excluídas do ordenamento jurídico, quando obstaculizem a investigação, processamento e condenação de responsáveis por graves violações de direitos humanos (Ver Caso Almonacid Arellano et al v. Chile, Caso Barrios Altos v. Peru, Caso Gelman v. Uruguai, Caso Gomes Lund et al ("Guerrilha do Araguaia") v. Brasil, Caso Massacres El Mozote e arredores v. El Salvado). Para as liberdades de pensamento e expressão e direitos político-eleitorais, ver Caso "A Última Tentação de Cristo" (Olmedo-Bustos et al) v. Chile, Caso Palamara Iribarne v. Chile, Caso Castañeda Gutman v. México (CALABRIA, C. 
Nestes casos, a CIDH elaborou sugestões de modificação das constituições e legislações locais, uma espécie de recomendação que se tornou comum no sistema interamericano desde o início dos anos 1990. Nas duas áreas temáticas seguintes, porém, a corte investiu também em medidas materiais e reformas da estrutura organizacional. Assim, quanto ao sistema carcerário e justiça criminal, recomendou por um lado a abolição de penas de punição corporal e a criação de regras processuais rígidas para, caso exista, pena de morte, mas por outro, também, recomendou o melhoramento da infraestrutura dos centros de detenção, por meio de protocolos de redução de acidentes, criação de ouvidorias e elaboração de sistema de registro de presos. ${ }^{20}$

O mesmo se pode dizer sobre o fortalecimento do Estado de direito, de suas instituições, garantias legais, procedimentos e normas. Aí, para a garantia do devido processo legal e do Estado democrático, a CIDH exigiu proteção do duplo grau de jurisdição e do devido processamento de habeas corpus, criação de programas de proteção de testemunhas e afastamento da prescrição para delitos de escravidão e delitos análogos. Exigiu também a proteção da independência judicial, como no caso Blanco Romero, em que ordenou à Venezuela cessar a remoção compulsória de juízes. ${ }^{21}$

Vale notar a tentativa de equilibrar medidas específicas o suficiente para terem efeito prático em casos de violação, mas também razoavelmente gerais para dar aos Estados autonomia para a constituição de seus ordenamentos jurídicos. O equilíbrio, tênue, é, como veremos, equivalente àquele presente nas tentativas de conceituação do Estado de direito. No caso Favela Nova Brasília, por exemplo, a CIDH reconheceu o problema da violência estrutural das organizações policiais contra a população negra e de baixa renda e exigiu do Estado brasileiro transparência e efetividade em crimes envolvendo agentes policiais. Ordenou, especificamente, a investigação por órgão independente da força policial envolvida, algo que pressupõe alteração da arquitetura institucional da segurança pública do país. ${ }^{22}$

Retomando o exemplo relativo à reforma do judiciário brasileiro, por um lado as recomendações da CIDH avançaram pouco em discutir os diversos modelos de organização institucional e as suas estratégias de implementação, até mesmo porque estes temas não são propriamente objeto de decisão e fundamentação judicial, mas sim inquirições de natureza teórica e empírica. Neste sentido, existem divergências quanto ao melhor modo de efetivar a investigação de crimes cometidos por agentes do Estado. Por outro lado, as recomendações certamente apontam limites da reforma do judiciário brasileiro, especialmente no que tange à segmentação da celeridade e efetividade dos processos judiciais. Se ambas as perspectivas, a adotada no Brasil e a promovida pela $\mathrm{CIDH}$, reconhecem a importância da segurança jurídica

\footnotetext{
Alterações normativas, transformações sociojurídicas: analisando a eficácia da Corte Interamericana de Direitos Humanos. Rev. Direito e Práx., Rio de Janeiro, v. 8, n. 2, pp. 1286-1355, 2017.).

${ }^{20}$ Ver Caso Pacheco Teruel et al v. Honduras, Caso Yvon Neptune v. Haiti, Casos Caso Fermín Ramírez v. Guatemala, Caso Lori Berenson Mejía v. Peru (CALABRIA, C. Alterações normativas, transformações sociojurídicas: analisando a eficácia da Corte Interamericana de Direitos Humanos. Rev. Direito e Práx., Rio de Janeiro, v. 8, n. 2, pp. 1286-1355, 2017).

${ }^{21}$ Ver Caso Blanco Romero et al v. Venezuela, Caso Favela Nova Brasília v. Brasil (CALABRIA, C. Alterações normativas, transformações sociojurídicas: analisando a eficácia da Corte Interamericana de Direitos Humanos. Rev. Direito e Práx., Rio de Janeiro, v. 8, n. 2, pp. 1286-1355, 2017).

${ }^{22}$ Ver Caso Favela Nova Brasília v. Brasil (CALABRIA, C. Alterações normativas, transformações sociojurídicas: analisando a eficácia da Corte Interamericana de Direitos Humanos. Rev. Direito e Práx., Rio de Janeiro, v. 8, n. 2, pp. 1286-1355, 2017).
} 
e da celeridade, apenas a última parece ter levado em consideração as diferenças reais ligadas à classe e raça, especialmente quando relativas à segurança e justiça criminal.

\section{REFORMAS INSTITUCIONAIS NO DIREITO E DESENVOLVIMENTO}

O estudo de reformas institucionais também se desenvolve no campo do direito e desenvolvimento e do institucionalismo histórico. Estes estudos, assim como os justiça de transição, destacam os fatores políticos nos processos de democratização. Compartilham a mesma dificuldade em definir o que seriam as reformas necessárias e prioritárias, uma vez que um modelo único dificilmente poderia ser estendido para os mais diversos contextos. Avançam, porém, principalmente na identificação de obstáculos e na elaboração de estratégias de implementação. Algumas destas estratégias são testadas, em seus estudos, em reformas da segurança pública, como veremos no tópico seguinte.

Em "Rule of Law Reform and Development: Charting the Fragile Path of Progress", Trebilcock e Daniels partem de um conceito minimalista de Estado de direito para identificar avanços e fracassos. ${ }^{23}$ A opção se justificaria, para os autores, como uma abordagem metodológica para comparação entre os processos de reforma em todo o mundo e como uma abordagem estratégica para sua implementação, uma vez que um conceito menos carregado facilitaria, por exemplo, a mobilização de aliados internacionais. Mesmo Trebilcock e Daniels, porém, reconhecem no campo teórico a natureza política do dilema de definição de projetos de desenvolvimento, que não se esgota em padrões de certeza jurídica e previsibilidade das decisões, tal como indicado em outras vertentes de estudos.

Por meio de uma análise empírica qualitativa, os autores identificam três razões para o fracasso das reformas institucionais. Primeiro, falta de recursos financeiros, tecnológicos e humanos para implementar as mudanças, de solução mais simples até pela existência de financiamentos internacionais, podendo, a depender do contexto, produzir a imagem enganosa um trabalho técnico consensual. Segundo, existência de fatores sociais, culturais e históricos que cristalizam valores, normas e práticas inóspitas mesmo a um conceito restrito de Estado de direito, mais problemático aos países do leste-europeu, de herança comunista, do que aos países da América Latina. Terceiro, existência de obstáculos de economia política, como grupos de interesse com poder de veto que de algum modo não são beneficiados. Prado, Trebilcock e Hartford acrescentam a estes fatores a ordem em que as reformas são colocadas

\footnotetext{
23 Para garantir a criação de um Estado de direito robusto, procedimentalmente orientado, as reformas institucionais deveriam incluir: (i) para o judiciário, auxílio material e redução de gargalos processuais; (ii) para acesso à justiça, criação de arranjos especiais para garantir a assistência coletiva e individual; (iii) para as promotorias, elaboração de programas educacionais de direitos humanos e de parâmetros de persecução em casos envolvendo direitos humanos e corrupção; (iv) para os órgãos de segurança, introdução de sistema de monitoramento de abusos e de mecanismos institucionais de desincentivo à corrupção; (v) para o sistema penal, incorporação das diretrizes das Nações Unidas, que incluem associação do sistema penal a mecanismos alternativos de resolução de conflitos, deslocamento da política de drogas para o âmbito das políticas sociais e de saúde, criação de penas alternativas à prisão; (vi) para a advocacia, promoção da autonomia; (vii) para o sistema tributário, adequação às necessidades e às possibilidades de arrecadação do país; e (viii) para o ensino jurídica, promoção de concepções pluralistas orientadas à realidade social. (TREBILCOCK, M; DANIELS, R. Rule of Law Reform and Development: Charting the Fragile Path of Progress. Cheltenham, UK: Edward Elgar, 2008).
} 
em prática, uma vez que decisões tomadas em fases iniciais podem mudar os arranjos políticos e criar impedimentos imprevistos, como novas práticas ou novos grupos de pressão. ${ }^{24}$

Para os autores, os obstáculos políticos, que orientam a identificação de prioridades e impasses políticos, seriam os decisivos para a condução de reformas bem sucedidas. Sua análise permitiria traçar estratégias, algumas das quais semelhantes às indicadas no campo de justiça transicional: (i) criação de instituições de produção de informações confiáveis e de instituições de monitoramento, se possível multilaterais, com a presença de agentes que tenham credibilidade, como funcionários aposentados e mídia independente; (ii) fomento de grupos locais e internacionais de pressão, incluindo lobby organizado, com listagem e mobilização de possíveis aliados, em especial para os casos em que as reformas beneficiam público disperso e a manutenção do estado de coisas beneficia grupos já estabelecidos; (iii) inclusão de condicionamentos de reformas em tratados internacionais de comércio; e (iv) criação de estratégias criativas de desbloqueio das resistências, como reincorporação dos agentes sob condição, em especial para os projetos de reforma em que se debate, como no caso da segurança, extinção de órgãos policiais. A última estratégia é semelhante à aventada pelo ICTJ sobre a socialização de membros de grupos armados desmobilizados.

Uma segunda linha teórica, que segue a constatação da natureza política dos impedimentos, analisa a natureza dos processos de reforma institucional no contexto latinoamericano. Complementa a anterior ao destacar os desafios próprios à região. $\mathrm{O}$ seu foco é direcionado não tanto à identificação das reformas que comporiam o núcleo central dos processos de redemocratização, mas sim à identificação dos desafios de implementação, por meio de uma comparação dos impasses enfrentados em países desenvolvidos e em países não desenvolvidos ou subdesenvolvidos.

Assim, ao comparar as reformas em países de indústria avançada com reformas nos países latino-americanos, a corrente chega a resultados interessantes. Murillo e Levitsky, primeiro, identificam os dois modelos de reformas próprias dos países de indústria avançada, tal como descritos em estudos de institucionalismo histórico. ${ }^{25}$ De um lado, estaria o modelo de "mudança gradual", o qual sustenta que na maior parte das vezes as reformas ocorrem por uma evolução gradual das instituições, pela utilização das regras do jogo em períodos normais, por atores que as subvertem, desviam ou redirecionam nas práticas cotidianas. ${ }^{26}$ De outro lado, estaria o modelo de "equilíbrio pontual", que sustenta que as instituições passam por longos períodos de continuidade intercalados por momentos de rápida transformação. Nos períodos de continuidade, os atores agem conforme regras formais ou informais previamente estabelecidas, seguindo um trajeto dependente (path dependence). Já nos períodos de crise (critical junctures), como nas transições políticas, o futuro se torna imprevisível e uma janela de oportunidade se abre para a negociação de novos acordos, que por sua vez serão cristalizados (lock in) e orientarão um novo trajeto dependente. Este modelo, como é de se imaginar, orientou boa parte dos estudos iniciais de transitologia, os quais argumentavam que as dificuldades para responsabilização de oficiais envolvidos em violações de direitos humanos

\footnotetext{
${ }^{24}$ PRADO, M; TREBILCOCK, M; HARTFORD, P. Police Reform in Violent Democracies in Latin America. Hague Journal on the Rule of Law, v. 4, n. 2, pp. 252-285, set. 2012

${ }^{25}$ MURILLO, M; LEVITSKY, S. Building Institutions on Weak Foundations: Lessons from Latin America. Johns Hopkins University Press, v. 24, n. 2, abr. 2013.

${ }^{26}$ MAHONEY, J; THELEN, K. Explaining Institutional Change: Ambiguity, Agency, and Power. New York: Cambridge University Press, 2010.
} 
permaneceriam no futuro se os pactos transicionais fossem acordados com membros do regime autoritário, como no caso brasileiro, pois tais pactos seriam estabilizados no tempo por meio de normas institucionais de difícil alteração. ${ }^{27}$

Como afirmam Murillo e Levitsky, nenhum dos dois modelos parece se adequar bem ao contexto latino-americano, uma vez que partem do pressuposto da existência de instituições e regras estáveis, sejam ou não intercaladas por períodos de crise. ${ }^{28}$ Mesmo nas transições latino-americanas estudadas por autores do "equilíbrio pontual", um amplo conjunto de regras implementadas durante a transição foi logo alterado. Tais alterações, ao contrário do previsto pelos autores da "mudança gradual" não teriam ocorrido de modo gradativo, mas por substituições bruscas. Assim, nos Estados Unidos e na Inglaterra, as reformas econômicas de liberalização de Ronald Reagan e Margaret Tatcher só atingiram instituições e programas do Estado de bem-estar social de modo progressivo e limitado. $\mathrm{Na}$ América Latina, em comparação, programas de liberalização dos anos 1990 transformaram bruscamente instituições de políticas sociais, como os regimes de previdência. O mesmo vale para os sistemas eleitorais, que na região latino-americana tiveram suas regras frequentemente alteradas a cada processo eleitoral de forma casuística por aqueles que chegavam aos órgãos de representação.

Para Murillo e Levitsky, a natureza distinta das reformas institucionais na América Latina decorre da existência de instituições precoces e transitórias, ancoradas na alta imprevisibilidade e na incongruência entre as regras formais e os interesses de reais detentores de poder. ${ }^{29}$ Isso por diversos motivos: instabilidade de regimes políticos, volatilidade eleitoral, importação de instituições, inexistência de atores sociais com poder de veto (como organizações da sociedade civil para controle externo), crises econômicas frequentes a justificar medidas executivas extremas e, principalmente, desigualdade social, que faz com que governos eleitos com base no voto universal superestimem a sua capacidade de efetivação de novas políticas e regras, podendo ser substituídos após curto período por outros atores com maior poder de fato.

Em alguns casos, continuam os autores, a própria não efetivação costumeira das regras formais pode ser um fator de estabilização política e institucional, o que é interessante para a compreensão da ausência de reformas em setores chave como a segurança. Quando as regras formais contrariam interesses de atores com poder de fato, a intensidade da oposição à instituição dependerá de quão efetivas são estas regras. Se puderem ser discricionariamente descumpridas, a oposição possivelmente será menor, com a vantagem de permanecerem válidas o suficiente para legitimação local e internacional.

É de se notar, no entanto, que mesmo nos casos em que as regras formais são usualmente não aplicadas elas podem ser reativadas em outro contexto, mediante o surgimento de novos atores e demandas. Assim, por exemplo, as regras de proteção ao trabalhador previstas formalmente na Constituição Federal de 1988 e usualmente descumpridas foram reativadas, nos anos 2000, pela melhoria de índices econômicos de pleno

\footnotetext{
${ }^{27}$ O'DONNELL, G; SCHMITTER, P; WHITEHEAD, L. Transitions from Authoritarian Rule. Londres: John Hopkins Univ. Press, 1986.

28 MURILLO, M; LEVITSKY, S. Building Institutions on Weak Foundations: Lessons from Latin America. Johns Hopkins University Press, v. 24, n. 2, abr. 2013.

${ }^{29}$ MURILLO, M; LEVITSKY, S. Building Institutions on Weak Foundations: Lessons from Latin America. Johns Hopkins University Press, v. 24, n. 2, abr. 2013.
} 
emprego e pelo fortalecimento de entes como as procuradorias do trabalho. Esta possibilidade de ativação posterior é uma vantagem estratégica em negociações de reformas, já que serve de ponto focal para uma futura mobilização da sociedade civil por vezes mais eficiente do que uma nova mobilização para alteração do enquadramento legal. ${ }^{30}$

Murillo e Levitsky não debatem ou elencam prioridades para as reformas institucionais no continente a partir de um determinado conceito de Estado de direito. ${ }^{31}$ Porém, apresentam dois desafios centrais, que remontam aos dilemas dos estudos de consolidação democrática da transitologia - dilemas, como vimos, ligados a concepções de rule of law e democracia. Primeiro, existiria uma tensão entre instituições desejáveis e estabilidade institucional. Reformas mais ambiciosas intensificariam a resistência e até a instabilidade política se efetivadas bruscamente. Seguindo O'Donnell et al, uma possível solução seria a criação destas instituições ambiciosas, que pudessem ser efetivadas progressivamente, por ativação futura pela sociedade civil, algo como uma "democratization on the installment plan". ${ }^{32}$ Progressão semelhante é sugerida por Prado, Trebilcock e Hartford para quem, em reformas do sistema de segurança, o problema inicial a ser enfrentado seria o respeito aos parâmetros do Estado de direito, como o controle de violência pelos agentes policiais, para só em momento seguinte se poder avançar à responsividade perante a sociedade civil. ${ }^{33}$

Segundo, existiria uma tensão entre instituições desejáveis e participação social. Em sociedades profundamente desiguais, a condução de reformas com a participação de grupos com poder de fato aumenta as suas chances de sucesso, embora possa reduzir a legitimidade do processo. Isso porque dá a eles um poder de veto sobre questões de seu interesse que não é dado a cidadãos comuns também interessados. Estes dilemas, como veremos, atravessam os diversos projetos de reforma institucional no Brasil.

\section{DESAFIOS PARA AS REFORMAS INSTITUCIONAIS NA SEGURANÇA PÚBLICA NO BRASIL}

Neste tópico, tentaremos tensionar os conceitos vistos acima em um estudo temático, o das reformas de segurança no Brasil. O desafio de implementação de reformas institucionais inclui, de um modo geral, ao menos três questões: a definição das áreas prioritárias, a seleção do modelo de reforma dentre aqueles disponíveis e o desenho das estratégias de negociação e efetivação. No que se refere ao campo da segurança pública, destas três questões apenas a primeira tem resposta relativamente consensual no âmbito teórico e prático, seja pela perspectiva da justiça de transição, seja dos estudos institucionalistas. Descreveremos alguns dos dilemas enfrentados no Brasil, retomando as perspectivas de análise da justiça de transição, do sistema interamericano de direitos humanos e dos estudos institucionalistas.

\footnotetext{
${ }^{30}$ COSLOVSKY, S; PIRES, R; BIGNAMI, R. Resilience and Renewal: The Enforcement of Labor Laws in Brazil. Latin American Politics and Society, v. 59, n. 2, 2017.

${ }^{31}$ MURILLO, M; LEVITSKY, S. Building Institutions on Weak Foundations: Lessons from Latin America. Johns Hopkins University Press, v. 24, n. 2, abr. 2013.

32 O'DONNELL, G; SCHMITTER, P; WHITEHEAD, L. Transitions from Authoritarian Rule. Londres: John Hopkins Univ. Press, 1986.

33 PRADO, M; TREBILCOCK, M; HARTFORD, P. Police Reform in Violent Democracies in Latin America. Hague Journal on the Rule of Law, v. 4, n. 2, pp. 252-285, set. 2012.
} 


\section{1 É preciso reformar o sistema de segurança?}

A segurança pública se tornou área prioritária em toda a América Latina por uma série de fatores. Inicialmente, podemos mensurá-la por meio de uma difusa sensação de insegurança, ainda que o processo de politização de um tema não se reduza à existência de preocupações individuais. Pelos dados do latinobarómetro, cerca de $43 \%$ das pessoas na América Latina preocupam-se "quase todo o tempo" em ser vítima de delitos com violência. ${ }^{34}$ Considerando dados de 2013 , com apenas $8 \%$ da população mundial, o continente latinoamericano produz $33 \%$ dos homicídios do mundo. Isso significa ao menos quatro a cada dez homicídios ocorre aqui. ${ }^{35}$ A Organização Mundial da Saúde considera epidêmica a taxa superior a 10 homicídios por cada 100 mil habitantes. Em 2015, a média das Américas foi de 18.6 vítimas por 100 mil habitantes, quase o dobro. Dentre os países da região, o Brasil tem o nono pior desempenho $(30,5)$, à frente apenas de Honduras $(85,7)$, El Salvador $(63,2)$, Venezuela $(51,7)$, Colômbia $(48,8)$, Belize $(37,2)$, Guatemala $(36,2)$, Jamaica $(35,2)$ e Trinidad e Tobago $(32,8) .{ }^{36}$

Estudo do IPEA mostra que o impacto econômico também é significativo. Estima-se que as mortes violentas no Brasil correspondam a uma redução de 2,36\% do PIB ao ano. 0 cálculo leva em consideração os valores que a população deixou de produzir e consumir. Acrescentando-se os gastos com tratamento das vítimas no sistema público de saúde, custeamento dos órgãos policiais $(1,4 \%)$, custeamento do sistema prisional $(0,4 \%)$ e segurança privada e seguro (1,6\%), o número salta a $5,9 \%$ do PIB. ${ }^{37}$

Enfrentar a violência, assim, é um passo necessário para produzir um Estado democrático, em quaisquer das perspectivas teóricas elencadas neste texto, seja a das diversas correntes de justiça de transição, seja a das correntes minimalista e maximalistas dos programas de desenvolvimento patrocinados pelo Banco Mundial. O desafio aqui, portanto, é identificar qual saída ou, conforme nosso objeto de estudo, qual reforma.

O primeiro passo é reconhecer que na América Latina, o direito à segurança exige não apenas uma atuação estatal menos arbitrária violenta - superando os anos de terror - mas também uma atuação eficiente na proteção do direito à vida e à integridade física. A segurança pública precisa ser pensada para além da afirmação do direito à saúde e à educação, como uma política pública que requer planejamento e investimentos próprios. Se a redução dos homicídios exige investimento em educação para crianças e jovens e em projetos esportivos e culturais, exige também controle de armamento, sistemas inteligentes de informação, tecnologia de monitoramento e melhoria na seletividade de entrada no sistema prisional, políticas que são elaboradas nos marcos do campo de conhecimento da segurança pública, compartilhado entre universidades, organizações sociais, secretarias de segurança e escolas de formação policial. Como se viu nas decisões do sistema interamericano de direitos humanos, o sistema criminal deve ser um objeto de reformas específicas.

\footnotetext{
${ }^{34}$ CORPORACIÓN LATINOBARÓMETRO. Informe 2016. Buenos Aires, 2016.

35 UNODC. Global Study on Homicide. United Nations Office on Drugs and Crimes, Genebra, 2013.

${ }^{36}$ WHO. World Report on Violence and Health, World Health Organisation, Genebra, 2015.

${ }^{37}$ CERQUEIRA, D; CARVALHO, A; LOBÃO, W; RODRIGUES, R. Análise dos Custos e Conseqüencias da Violência no Brasil. Texto para discussão n. 1284. Brasília, junho de 2007.
} 
Indo um passo além, é interessante notar, porém, que existem indícios de que as duas vertentes, a atuação estatal menos arbitrária e a atuação estatal eficiente, na realidade caminham juntas. Em estudo sobre a relação entre os direitos de integridade física - definidos como tortura, execução sumária, desaparecimento forçado e aprisionamento político - e a persecução penal de crimes cometidos por agentes dos regimes autoritários, Katherine Sikkink e Hunjoon Kim demonstram existir correlação positiva, ou seja, influência relevante. ${ }^{38}$ Considerando dados a partir de 1995, após a última onda de transições, países que processaram os agentes políticos pelos crimes cometidos em períodos de exceção, independentemente de os processos terem resultado em absolvição ou condenação, possuem taxas de proteção de direitos de integridade física constantemente melhores do que a média global e do que a média de países que não levaram adiante estes processos. ${ }^{39} \mathrm{O}$ resultado se mantém ainda quando são controlados estatisticamente os outros fatores relevantes, como a existência de guerra civil. O resultado não é definitivo, uma vez que os autores levam em consideração apenas os crimes de tortura, execução sumária, desaparecimento forçado e aprisionamento político, não homicídio comum. No entanto, dão indícios, para futuros estudos, para a conclusão de que o controle da violência de agentes estatais acompanha a redução da violência difusa.

Os passos seguintes são objeto de maiores divergências. Deveria a polícia no Brasil ser reorganizada para realizar suas atividades em ciclo completo? Ou seja, ser reorganizada para que uma só organização policial fosse responsável pela prevenção, repressão e investigação dos crimes, seja utilizando o critério de repartição material, pelo qual polícia civil e militar seriam diferenciadas pelo tipo de crime, seja utilizando o critério de repartição territorial, pelo qual seriam diferenciadas pelo território protegido. Deveria a polícia militar - que é responsável atualmente pelo policiamento ostensivo, aquele feito em contato direto com a população nas ruas - ser extinta ou desmilitarizada, passando a se organizar em carreira civil, com outros parâmetros de comando, associação e responsabilização? Deveriam os órgãos de controle - de investigação de crimes de agentes do Estado - ser externos ou internos? Em que medida estas e outras alterações podem efetivamente promover o controle da violência de Estado e a eficiência na proteção da sociedade? Que medidas são prioritárias e como implementá-las? Selecionamos aqui dois dos desafios legados à segurança pública.

\subsection{A reforma e a estratégia de implementação: entre o Estado de direito e a sociedade}

O problema da militarização exige reflexão sobre o papel da polícia e sobre as especificidades, historicamente construídas, da polícia militar no Brasil. Como lembra Prado, Trebilcock e Hartford (2012) existem, em todo o mundo, ao menos dois desafios distintos: (i) o descolamento dos agentes policiais em relação aos padrões do Estado de direito, ligado à prática corrente de violações cometidas pelas forças de segurança; e (ii) o descolamento dos agentes policiais em relação aos interesses da sociedade, ligado ao sujeito a quem se presta contas, podendo o agente estar adstrito à própria organização policial autônoma,

\footnotetext{
${ }^{38}$ SIKKINK, K; KIM, H. J. The Justice Cascade: The Origins and Effectiveness of Prosecutions of Human Rights Violations. Annu. Rev. Law Soc. Sci., 2013.

39 SIKKINK, K; KIM, H. J. The Justice Cascade: The Origins and Effectiveness of Prosecutions of Human Rights Violations. Annu. Rev. Law Soc. Sci., 2013, p. 368.
} 
instrumentalizado por determinados setores governamentais ou ainda alinhado às demandas da sociedade civil. ${ }^{40}$ Assim, nem toda polícia organizada de modo fechado, responsiva apenas aos seus parâmetros internos, é violenta e corrupta. O exemplo normalmente citado é o da polícia militar do Chile, que possui baixas taxas de violações de direitos fundamentais por parte de seus agentes. Também nem toda polícia que se alinha à sociedade respeita os limites do Estado de direito. Uma sociedade que aceita o discurso de "bandido bom é bandido morto" pode ser resistente à redução das taxas de atuação estatal arbitrária. ${ }^{41}$

Em certa medida, inexiste consenso sobre a conexão entre os dois desafios. Alexandre Rocha, ao comparar as polícias militares do Chile e do Brasil, sustenta que a maior taxa de violência policial no Brasil se explicaria pelo modelo particularmente fechado adotado desde o regime militar. ${ }^{42}$ Segundo Rocha, polícias militares, em virtude do modelo hierarquizado, são naturalmente propícias a um espírito de corpo fechado. Contudo, ao menos em comparação ao Chile, Brasil se destacaria pela criação de organizações especialmente insuladas. De fato, a militarização da segurança pública entre 1964 e 1988 pode ser compreendida como um processo de burocratização conservadora que equilibrou autonomia e instrumentalização política. ${ }^{43}$ As polícias adquiriram mais recursos e competências portanto mais condições de atuação, mais autonomia - para que pudessem ser instrumentalizadas, ou seja, para que pudessem executar as políticas definidas pelos órgãos políticos superiores. ${ }^{44}$ Os mecanismos de controle criados neste período serviram para repreender as violações consideradas inapropriadas, assim como para uniformizar a atuação nos parâmetros da doutrina de segurança nacional.

Para descrever em detalhe, em 1967, o Decreto-Lei Federal n. 317/67 federalizou o controle e a direção da segurança pública, mantendo a execução direta nos Estados. O decreto criou um órgão de controle nacional, a Inspetoria Geral das Polícias Militares, responsável pela fiscalização, coordenação e normatização de todas as polícias do país; formalizou o controle das nomeações para secretários de segurança; tornou obrigatória a indicação de generais para comandantes de polícia, autorizando apenas excepcionalmente que fosse um agente do último posto da carreira; ainda, militarizou o policiamento ostensivo, aquele que se faz nas ruas em contato direto com a população e que, até então, no caso de São Paulo, era repartido com a Guarda Civil, ficando com a última a maior parcela de policiamento das grandes cidades, salvo nas áreas adjacentes aos quarteis. ${ }^{45}$

Neste último aspecto, o diploma legal gerou dúvidas e insatisfação entre os quadros da segurança, principalmente junto às polícias civis que vinham exercendo a atribuição. Em

\footnotetext{
40 PRADO, M; TREBILCOCK, M; HARTFORD, P. Police Reform in Violent Democracies in Latin America. Hague Journal on the Rule of Law, v. 4, n. 2, pp. 252-285, set. 2012.

${ }^{41}$ NUNES, S. Bandido bom é bandido morto: a opção ideológico-institucional da política de segurança pública na manutenção de padrões de atuação violentos da polícia militar paulista. 2014. 146 f. Dissertação (Mestrado em Administração de Empresas) - FGV, São Paulo - SP.

${ }^{42}$ ROCHA, A. P. A gramática das polícias militarizadas: estudo comparado entre a Polícia Militar do Estado de São Paulo - Brasil e Carabineros - Chile em regimes políticos autoritários e democráticos. 2013. 314 f. Tese (Doutorado no Centro de Pesquisa e Pós-Graduação das Américas) - UnB, Brasília - DF.

${ }^{43}$ GUERRA, M. P. Polícia e Ditadura: arquitetura institucional da segurança pública de 1964 a 1988. Brasília: Ministério da Justiça / Comissão de Anistia, 2016.

${ }^{44}$ MUNIZ, J. A Crise de Identidade das Polícia Militares Brasileiras: Dilemas e Paradoxos da Formação Educacional. Security and Defense Studies Review, v. 1, p. 177-198, 2001, p. 184.

${ }^{45}$ GUERRA, M. P. Polícia e Ditadura: arquitetura institucional da segurança pública de 1964 a 1988. Brasília: Ministério da Justiça / Comissão de Anistia, 2016.
} 
1969, a dúvida foi solucionada por meio do Decreto-Lei Federal n. 667/69, que tornou o policiamento ostensivo uma atribuição exclusiva das polícias militares. Reforçou também a ingerência do ministério do Exército, formalizando uma dupla cadeia de comando das polícias ao governo estadual e às forças armadas. Ao final daquele ano, o governo federal determinou que todos os Estados extinguissem as guardas civis e criassem uma polícia militar (Decreto Federal n.o 1.072/69). Seguindo o novo modelo, em 1970, por meio do regulamento das polícias militares (Decreto Federal $n .066 .862 / 70$ ), as forças armadas ampliaram o escopo de atuação das polícias para a persecução de atividades subversivas e ampliaram o controle federal por meio de subordinação no planejamento, execução operacional e definição de material bélico, efetivo e localização das unidades policiais.

Esta instrumentalização recebeu novos contornos a partir de 1988. As polícias deixaram de se vincular às forças armadas, mas não chegaram a promover, ao menos imediatamente, um vínculo maior com a sociedade civil. Órgãos de controle externo com participação da sociedade civil, como as ouvidorias de polícia, só foram criados durante os anos 1990 e ainda assim, até hoje, permanecem sem estrutura e condições de trabalho. ${ }^{46}$ Mesmo a inovação da Constituição Federal de 1988 no sistema de controle, que foi a atribuição dada ao Ministério Público para controle externo das polícias, foi insuficientemente efetivada aos longo dos anos, como reconhecem os próprios procuradores e promotores públicos. ${ }^{47}$ Ainda, existem nos dias de hoje denúncias de um outro tipo de instrumentalização política, a da indicação por lideranças políticas locais para a nomeação para comandos policiais. ${ }^{48} \mathrm{~A}$ perda do liame de instrumentalização, portanto, mesmo quando levada adiante, não induziu imediatamente à melhoria dos padrões de atuação conforme o direito.

Prado, Trebilcock e Hartford partem desta dicotomia para sugerir uma ordem para a efetivação de reformas na polícia, na linha de raciocínio elaborada por Trebilcock e Daniels, que busca estratégias de desvio das resistências políticas. ${ }^{49} \mathrm{~A}$ prioridade deveria ser vincular as polícias a padrões de legalidade, para só em um segundo momento buscar reorganizá-las para se tornarem responsivas à sociedade civil, o que incluiria, avançam, a desmilitarização. $A$ dificuldade em aceitar o argumento, porém, surge quando pensamos nos incentivos capazes de fomentar as alterações na estrutura, se bastam aqueles oriundos da própria organização. Tal como enunciado no estudo de Samira Nunes, o marco inicial para reformas na polícia militar durante os anos 1990 foi o episódio da Favela Naval, o qual, por ter abalado a credibilidade social da polícia militar, serviu de incentivo externo para uma revisão interna dos padrões de conduta. ${ }^{50} \mathrm{~A}$ abertura social é, assim, fator relevante para mudanças em qualquer dos dois desafios.

\footnotetext{
${ }^{46}$ CANO, I; DUARTE, T; LIMA, R. As corregedorias dos órgãos de segurança pública no Brasil: nota técnica de pesquisa. Brasília, dez. 2014.

47 CASTILHO, E; SADEK, M. O Ministério Público federal e a Administração da Justiça no Brasil. São Paulo: IDESP/Sumaré, 1998.

${ }^{48}$ RAUL Jungmann diz que não haverá indicações políticas na polícia durante intervenção no Rio. O Globo, Rio de Janeiro, 6 abr. 2018.

49 PRADO, M; TREBILCOCK, M; HARTFORD, P. Police Reform in Violent Democracies in Latin America. Hague Journal on the Rule of Law, v. 4, n. 2, pp. 252-285, set. 2012. Também: TREBILCOCK, M; DANIELS, R. Rule of Law Reform and Development: Charting the Fragile Path of Progress. Cheltenham, UK: Edward Elgar, 2008

${ }^{50}$ NUNES, S. Bandido bom é bandido morto: a opção ideológico-institucional da política de segurança pública na manutenção de padrões de atuação violentos da polícia militar paulista. 2014. 146 f. Dissertação (Mestrado em Administração de Empresas) - FGV, São Paulo - SP.
} 
De toda forma, como estratégia de implementação, pode ser produtivo concentrar os esforços iniciais para a redução dos índices de atuação arbitrária e de corrupção, deixando para etapa seguinte a reorganização interna e desmilitarização. As resistências à desmilitarização parecem ser maiores do que as resistências à vinculação aos padrões de legalidade, o que se explica pelo modo como as instituições criam os seus trajetos dependentes (path dependence): a militarização, uma vez instituída, orientou gerações de agentes policiais a se dedicar para a adequação aos critérios hierárquicos e corporativos de promoção na carreira. A alteração de estruturas organizacionais pode colocar a perder esforços acumulados em toda uma vida.

Mesmo como estratégia de implementação, no entanto, é preciso levar em conta a efetividade da proposta. Luiz Eduardo Soares, neste caminho, critica a militarização pela pouca eficiência em relação aos objetivos do policiamento. ${ }^{51} \mathrm{O}$ argumento, vale notar, é semelhante ao sustentado por Sikkink e Kim sobre a relação entre controle e redução da violência estatal. ${ }^{52}$ Para o autor, as polícias militares estão submetidas a um modelo organizacional que, espelhado nas forças armadas, sendo fortemente verticalizado e rígido, é inapto ao cumprimento de sua missão. Confrontos quase-bélicos, que poderiam validar uma atuação espelhada nas forças armadas, correspondem a menos do que $1 \%$ das atividades da polícia militar. $O$ restante das atividades teria natureza preventiva e exigiria do policial uma atuação de gestor da política de segurança no território, uma atuação que é bastante distinta daquela de soldado que executa as ordens ditadas por seus superiores. A atividade de policiamento exigiria a presença uniformizada e ostensiva, mas igualmente a "descentralização; valorização do trabalho na ponta; flexibilidade no processo decisório nos limites da legalidade, do respeito aos direitos humanos e dos princípios internacionalmente concertados que regem o uso comedido da força; plasticidade adaptativa às especificidades locais; capacidade de interlocução, liderança, mediação e diagnóstico; liberdade para adoção de iniciativas que mobilizem outros segmentos da corporação e intervenções governamentais inter-setoriais". ${ }^{53}$ Neste sentido, apenas uma organização civil seria capaz de dar autonomia e cobrar responsabilidade dos gestores que atuam na ponta.

Por fim, é importante notar que mesmo a opção pela permanência da militarização como estratégia inicial ou como concessão às carreiras existentes - deve incluir, para que se conforme aos padrões mínimos de um Estado de direito, a elaboração de critérios de responsividade e, assim, constitucionalização de parte dos códigos de conduta policiais utilizados no Brasil. Isso envolve, em alguma medida, repensar também as estratégias de ação. Uma orientação institucional para o flagrante que ocorre no policiamento ostensivo, à diferença da orientação para a investigação inteligente, acaba por intensificar a repressão a grupos negros de classe baixa, sem garantia de eficiência na segurança.

Para concluir, é possível dizer que, diferentemente do que destaca uma linha de interpretação no campo da justiça de transição, o problema maior da militarização não é tanto a origem da violência, se iniciada ou aprofundada com as alterações promovidas pelo regime militar. A obsessão com a origem, aliás, é uma das limitações deste campo teórico, pois

\footnotetext{
51 SOARES, L. E. Arquitetura Institucional da Segurança Pública no Brasil: Três propostas de Reforma Constitucional. Rio de Janeiro, 2012.

52 SIKKINK, K; KIM, H. J. The Justice Cascade: The Origins and Effectiveness of Prosecutions of Human Rights Violations. Annu. Rev. Law Soc. Sci., 2013.

53 SOARES, L. E. Arquitetura Institucional da Segurança Pública no Brasil: Três propostas de Reforma Constitucional. Rio de Janeiro, 2012.
} 
obscurece desigualdades anteriores e posteriores às ditaduras. A violência contra a população negra é em muito anterior, já que remonta ao período escravocrata, mas é também posterior, em sua forma contemporânea de controle social, pois ressurge com a política de encarceramento em massa intensificada nos anos 2000. O problema da militarização, ao contrário, deve ser analisado diante dos seus efeitos para a manutenção do atual estado de coisas, levando em consideração o modelo adequado à efetiva proteção dos cidadãos dentro do Estado de direito e a estratégia política que permitirá a sua implementação.

\subsection{A reforma e a estratégia de implementação: entre o governo federal e os entes locais}

O segundo desafio da segurança pública diz respeito ao regime constitucional federativo. Durante o regime militar, como vimos, em virtude da influência da doutrina de segurança nacional, a segurança interna foi federalizada: a direção foi progressivamente absorvida pelo governo federal militar, embora a manutenção direta tenha sido mantida em mãos dos Estados. ${ }^{54}$ Durante a redemocratização, em decorrência de um desgaste social do autoritarismo e de um fortalecimento dos governadores após as eleições de 1982, o sistema de segurança foi parcialmente alterado, mas a única modificação relevante foi a descentralização. As competências retornaram aos Estados, mas a organização interna permaneceu a mesma.

Neste período, alguns Estados, como Rio de Janeiro e São Paulo, buscaram reformar as polícias. O sucesso, no entanto, foi mínimo. Em ambos os casos as organizações policiais, receosas pelo seu futuro, reagiram fortemente a quaisquer medidas de intervenção em sua estrutura. No caso de São Paulo, por exemplo, o projeto inicial do governador Franco Montoro foi logo alterado em tentativa de mitigar a rejeição, deixando de prever o fortalecimento das corregedorias para priorizar as academias de polícia, que afetariam de modo mais intenso apenas os futuros integrantes. Como mostra Mingardi - e, pode-se acrescentar, Murillo e Levitsky - a estabilidade das polícias dependia em alguma medida de uma baixa efetividade das regras legais. Uma reforma no sistema de controle precisaria ser gradual. ${ }^{55}$

Durante a Assembleia Nacional Constituinte, o modelo foi constitucionalizado. 0 resultado foi um sistema paradoxalmente descentralizado e engessado. Descentralizado porque a competência material ficou com os Estados, sem previsão de responsabilidade para União e Municípios, à exceção de uma futura lei nacional de organização das polícias e de atribuição para criar guardas para proteção de bens e serviços municipais (art. 144, § 7ㅇ e 8ㅇ). Engessado porque, conforme orientação do Supremo Tribunal Federal nos anos seguintes, as competências seriam típicas, sem margem para adaptação aos interesses locais e sem instrumentos adequados para a articulação entre os atores (organizações policiais e entes federativos).

Isso não quer dizer que União e Municípios tenham ficados ausentes do debate. Após um período inicial de abstenção, a partir de meados dos anos 1990 o governo federal deu início a uma série de projetos no setor. A primeira experiência relevante ocorreu no governo

\footnotetext{
54 Decreto-lei federal n. 317/67, o Decreto-Lei Federal n. 667/69 e o Decreto Federal n.ㅇ 66.862/70.

${ }^{55}$ MINGARDI, G. Tiras, Gansos e Trutas: cotidiano e reforma na Polícia Civil. São Paulo: Scritta, 1992. Também: MURILLO, M; LEVITSKY, S. Building Institutions on Weak Foundations: Lessons from Latin America. Johns Hopkins University Press, v. 24, n. 2, abr. 2013.
} 
Fernando Henrique Cardoso, com o Plano Nacional de Segurança Pública, a ser executado com recursos de um novo Fundo Nacional de Segurança Pública, por meio da Secretaria Nacional de Segurança Pública (SENASP). A segunda, já no governo Lula, ocorreu com o Programa Nacional de Segurança Pública com Cidadania (PRONASCI), que ampliou atuação e orçamento, prevendo investir cerca de $R \$ 6$ bilhões até 2012. Também os municípios foram politicamente forçados a adentrar no setor. De 2000 a 2015, o volume de gastos municipais na segurança passou de $0.03 \%$ para $0.08 \%$ do PIB. ${ }^{56}$

O problema, porém, é a ausência de parâmetros comuns. Sem uma coordenação estratégica nacional, que defina, por exemplo, protocolos de registro, inexistem sequer informações sistematizadas capazes de subsidiar políticas públicas. ${ }^{57}$ Da mesma forma, sem uma repartição de competências federais adequada, sobrepõem-se as atribuições das organizações policiais estaduais e guardas municipais, sem garantia de eficiência. A ausência de um sistema com integração entre os órgãos e entes federativos, parâmetros de gasto e de metas, tal como vem sendo construído para a saúde e educação, faz com que as políticas de segurança sejam conduzidas com improvisação e ineficiência.

Neste sentido, para a reforma do sistema de segurança, não basta refletir sobre aqueles preceitos que tradicionalmente estão vinculados ao estudo dos direitos humanos, como os protocolos de uso da força, o acesso ao habeas corpus, a existência de uma justiça militar. É preciso avançar também na estrutura de gestão e financiamento. Saber se a melhor política é a da Garantias de Lei e Ordem ou da Intervenção Federal no Rio de Janeiro, por exemplo, é, em grande medida, uma questão de política pública, gestão da administração e gestão de recursos financeiros, que deve levar em consideração o alto custo e a baixa clareza quanto às metas a ser alcançadas. Inclui o obstáculo material, anunciado por Trebilcock e Daniels, especialmente em tempos de carência financeira. ${ }^{58}$

De toda forma, é interessante realizar aqui um contraponto a Murillo e Levitsky. ${ }^{59} \mathrm{Se}$ a América Latina produziu historicamente reformas bruscas, isso é apenas parcialmente verdadeiro para a segurança pública. O Brasil formulou, por um lado, seguidas políticas públicas de segurança marcadas pela descontinuidade, como são, por exemplo, as temporárias GLO's. No entanto, por outro, foi incapaz de realizar uma reforma estrutural. Neste aspecto, parece ter força o argumento institucionalista do path dependence: uma vez inseridos na organização, os agentes da segurança reagem às mudanças.

\footnotetext{
${ }^{56}$ PERES, U; BUENO, S; TONELLI, G. Os Municípios e a Segurança Pública no Brasil: uma análise da relevância dos entes locais para o financiamento da segurança pública desde a década de 1990. Rev. bras. de seg. púb, São Paulo, v. 10, n. 2, pp. 36-56, Ago/Set 2016.

${ }^{57}$ FIGUEIREDO, I. A Gestão de Informações e o Papel da Senasp. In: IPEA. Boletim de Análise Político-Institucional, Política Nacional de Segurança Pública, n. 11. Brasília, 2017.

58 TREBILCOCK, M; DANIELS, R. Rule of Law Reform and Development: Charting the Fragile Path of Progress. Cheltenham, UK: Edward Elgar, 2008.

59 MURILLO, M; LEVITSKY, S. Building Institutions on Weak Foundations: Lessons from Latin America. Johns Hopkins University Press, v. 24, n. 2, abr. 2013.
} 


\section{CONSIDERAÇÕES FINAIS}

O estudo das reformas da segurança é beneficiado pelas contribuições das duas áreas de conhecimento aqui analisadas: justiça de transição, incluindo sua relação com os direitos humanos, e direito e desenvolvimento em sua vertente institucionalista. As duas áreas convergem ao reconhecer a necessidade e mesmo urgência, no caso brasileiro, de uma reforma nas políticas de segurança pública. Iluminam, porém, aspectos distintos e em geral complementares.

Os estudos de justiça de transição traçam uma linha de continuidade entre o período autoritário de 1964 a 1988 e o modelo de segurança pública violento e ineficiente dos dias de hoje. Embora seja preciso mediar o argumento em relação à muito anterior violência estatal, é preciso também reconhecer o seu acerto no que se refere à organização institucional. Como vimos, a arquitetura institucional de segurança pública, com sua falta de coordenação entre os atores federativos e organizações policiais, tem suas raízes nas opções legislativas e constitucionais do regime militar e da redemocratização.

Tanto os estudos de justiça transicional como as recomendações da Corte Interamericana de Direitos Humanos destacam a segmentação social dos desafios e das soluções. Por certo, os autores do direito e desenvolvimento analisados já reconhecem tal segmentação ao apresentar os obstáculos gerais e latino-americanos de natureza política. Os primeiros, partindo desta preocupação, avançam para a sugestão de modelos de reforma, como a criação de órgãos externos de investigação. De uma ou outra perspectiva, mostram ser imperativo ao Brasil ter em conta o impacto diferenciado das ações de segurança sobre raças e classes sociais. Uma reforma que desconsidere a desigualdade social, independentemente do modelo, peca pela ausência de legitimidade.

Talvez a principal contribuição dos estudos institucionalistas de direito e desenvolvimento seja o foco na dinâmica de concepção e efetivação das reformas, ou, nas palavras dos autores, na análise dos obstáculos. Sem esta contribuição, não existe avanço prático na solução dos problemas da segurança. Vimos presentes os três obstáculos indicados por Trebilcock e Daniels: os materiais, intensificados em período de crise fiscal, os culturais, resumidos na ideia de bandido bom e morto, e os políticos, os quais, principalmente, atravessaram as diversas tentativas de reformulação das políticas do setor. ${ }^{60}$ Estes últimos ora configuraram empecilhos próprios das organizações policiais, como o fechamento do espírito de corpo, analisado sob a perspectiva do path dependence. Ora configuraram empecilhos próprios da América Latina, como a opção por seguidas políticas provisórias ou por regulamentos de baixo enforcement. Não à toa, os autores deste campo sugerem atuação estratégica, com prévia escolha das prioridades e da ordem cronológica de implementação, a qual poderia, ainda, incluir uma dilatação temporal da efetivação (democratization on the installment plan). Sugerem, ainda, envolver os agentes afetados nas mudanças propostas, no intuito de amenizar futuras resistências à implementação.

A reforma de segurança pública é hoje um dos desafios por ser enfrentados. O sucesso da empreitada, porém, exigirá não apenas vontade política, mas também apoio em estudos científicos que demonstrem os acertos e os equívocos de ideias generalizadas e pouco

60 TREBILCOCK, M; DANIELS, R. Rule of Law Reform and Development: Charting the Fragile Path of Progress. Cheltenham, UK: Edward Elgar, 2008. 
amparadas por dados. Exigirá também, identificação dos diversos grupos sociais atuantes e suas respectivas demandas, no intuito de prever resistências e buscar formas criativas de sua superação.

\section{REFERÊNCIAS}

ABRÃO, P; TORELLY, M. O programa de reparações como eixo estruturante da Justiça de Transição no Brasil. In: F Reátegui (org.). Justiça de Transição: Manual para a América Latina. Brasília/Nova lorque: Ministério da Justiça/ICTJ, 2011, p. 473-516.

BAYLEY, D. Law Enforcement and the Rule of Law: Is there a Tradeoff? Criminology \& Public Policy, v. 2, n.1, 2002.

CALABRIA, C. Alterações normativas, transformações sociojurídicas: analisando a eficácia da Corte Interamericana de Direitos Humanos. Rev. Direito e Práx., Rio de Janeiro, v. 8, n. 2, pp. 1286-1355, 2017.

CANO, I; DUARTE, T; LIMA, R. As corregedorias dos órgãos de segurança pública no Brasil: nota técnica de pesquisa. Brasília, dez. 2014.

CASTILHO, E; SADEK, M. O Ministério Público federal e a Administração da Justiça no Brasil. São Paulo: IDESP/Sumaré, 1998.

CAROTHERS, T. The Rule of Law Revival. Foreign Affairs, v. 77, n. 95, 1998.

CERQUEIRA, D; CARVALHO, A; LOBÃO, W; RODRIGUES, R. Análise dos Custos e Conseqüencias da Violência no Brasil. Texto para discussão n. 1284. Brasília, junho de 2007.

CORPORACIÓN LATINOBARÓMETRO. Informe 2016. Buenos Aires, 2016

COSLOVSKY, S; PIRES, R; BIGNAMI, R. Resilience and Renewal: The Enforcement of Labor Laws in Brazil. Latin American Politics and Society, v. 59, n. 2, 2017.

DAKOLIAS, M. O setor judiciário na América Latina e no Caribe: Elementos para reforma. Documento técnico n. 319, Banco Mundial. Nova lorque: Banco Mundial, 1996.

DANIELS, R; TREBILCOCK, M. The Political Economy of Rule of Law Reform in Developing Countries. Michigan Journal of International Law, v. 26, n. 1, 2004.

FERNANDO, B. Editorial: Institutional Reforms as an Integral Part of a Comprehensive Approach to Transitional Justice. International Journal of Transitional Justice, v. 8, 2014, 187193.

FIGUEIREDO, I. A Gestão de Informações e o Papel da Senasp. In: IPEA. Boletim de Análise Político-Institucional, Política Nacional de Segurança Pública, n. 11. Brasília, 2017.

GUERRA, M. P. Polícia e Ditadura: arquitetura institucional da segurança pública de 1964 a 1988. Brasília: Ministério da Justiça / Comissão de Anistia, 2016.

HAYNER, P. Unspeakable truths. Facing the challenge of Truth Commissions. 2 ed. New York, London: Routledge, 2010.

KAUFMANN; KRAAY; MASTRUZZI. Governance Matters VI: Governance Indicators for 19962006. World Bank Policy Research Working Paper n. 4280, jul. 2007. 
LIGH, M; PRADO, M; WANG, Y. Policing Following Political and Social Transitions: Russia, Brazil, and China Compared. Theoretical Criminology, v. 19, n. 2, pp. 216-238, 2015.

MAHONEY, J; THELEN, K. Explaining Institutional Change: Ambiguity, Agency, and Power. New York: Cambridge University Press, 2010.

MAYER-RIECKH, A; GREIFF, P. Justice as Prevention: Vetting Public Employees in Transitional Societies. Nova lorque: Social Science Research Council, 2007.

MINGARDI, G. Tiras, Gansos e Trutas: cotidiano e reforma na Polícia Civil. São Paulo: Scritta, 1992.

MUNIZ, J. A Crise de Identidade das Polícia Militares Brasileiras: Dilemas e Paradoxos da Formação Educacional. Security and Defense Studies Review, v. 1, p. 177-198, 2001.

MURILLO, M; LEVITSKY, S. Building Institutions on Weak Foundations: Lessons from Latin America. Johns Hopkins University Press, v. 24, n. 2, abr. 2013.

NAÇÕES UNIDAS. Guidance Note of the Secretary-General: United Nations Approach to Transitional Justice. Nova lorque, março de 2010. Disponível em: < https://www.un.org/ruleoflaw/files/TJ_Guidance_Note_March_2010FINAL.pdf>. Acesso em 20 de junho de 2018.

NAGY, R. Transitional Justice as Global Project: critical reflections. Third World Quarterly, v. 29, n. 2, pp. 275-289, 2008.

NORTH, D.C. Institutional Change: a framework of analyses. 1999. Disponível em http://ecsocman.hse.ru/data/853/760/1216/9412001.pdf. Acesso 28 de junho de 2012.

NUNES, S. Bandido bom é bandido morto: a opção ideológico-institucional da política de segurança pública na manutenção de padrões de atuação violentos da polícia militar paulista. 2014. 146 f. Dissertação (Mestrado em Administração de Empresas) - FGV, São Paulo - SP.

O'DONNELL, G; SCHMITTER, P; WHITEHEAD, L. Transitions from Authoritarian Rule. Londres: John Hopkins Univ. Press, 1986.

OSMO, C. Judicialização da justiça de transição na América Latina. Brasília: Ministério da Justiça, Comissão de Anistia, Rede Latino-Americana de Justiça de Transição, 2016.

PEREIRA, A; UNGAR, M. The Persistence of Mano Dura: Authoritarian Legacies and Policing in Brazil and the Southern Cone. In: HITE; CESARINI (ed). Authoritarian Legacies and Democracy in Latin America and Southern Europe. Notre Dame: University of Notre Dame Press, 2004.

PERES, U; BUENO, S; TONELLI, G. Os Municípios e a Segurança Pública no Brasil: uma análise da relevância dos entes locais para o financiamento da segurança pública desde a década de 1990. Rev. bras. de seg. púb, São Paulo, v. 10, n. 2, pp. 36-56, Ago/Set 2016.

PRADO, M. The paradox of rule of law reforms: how early reforms can create obstacles to future ones. Rev. Sociol. Politica, Curitiba, v. 21, n. 45, mar. 2013.

PRADO, M; TREBILCOCK, M; HARTFORD, P. Police Reform in Violent Democracies in Latin America. Hague Journal on the Rule of Law, v. 4, n. 2, pp. 252-285, set. 2012.

RAUL Jungmann diz que não haverá indicações políticas na polícia durante intervenção no Rio. O Globo, Rio de Janeiro, 6 abr. 2018. 
ROCHA, A. P. A gramática das polícias militarizadas: estudo comparado entre a Polícia Militar do Estado de São Paulo - Brasil e Carabineros - Chile em regimes políticos autoritários e democráticos. 2013. 314 f. Tese (Doutorado no Centro de Pesquisa e Pós-Graduação das Américas). UnB, Brasília, DF.

SIKKINK, K; KIM, H. J. The Justice Cascade: The Origins and Effectiveness of Prosecutions of Human Rights Violations. Annu. Rev. Law Soc. Sci., 2013.

SOARES, L. E. Arquitetura Institucional da Segurança Pública no Brasil: Três propostas de Reforma Constitucional. Rio de Janeiro, 2012. Disponível em: <http://www.luizeduardosoares.com/?p=997>. Acesso em 25 abr. 2016.

TEITEL, R. Transitional Justice. New York: Oxford University Press, 2000.

TREBILCOCK, M; DANIELS, R. Rule of Law Reform and Development: Charting the Fragile Path of Progress. Cheltenham, UK: Edward Elgar, 2008.

UNODC. Global Study on Homicide. United Nations Office on Drugs and Crimes, Genebra, 2013.

WEICHERT, M. The role of institutional reform in transitional justice and the obstacles for its development. Trabalho apresentado na Global Fellows Forum, Hauser Global Program, New York University. Nova lorque, 7 out. 2014.

WHO. World Report on Violence and Health, World Health Organisation, Genebra, 2015. 